\title{
ENERGY OF BIOMASS
}

\section{ТЕХНОЛОГИЯ ПРОИЗВОДСТВА И ИСПОЛЬЗОВАНИЕ БИОМАССЫ МИКРОВОДОРОСЛЕЙ ТОПЛИВНОГО НАЗНАЧЕНИЯ}

\author{
В.Г. Чирков, Ю.А. Кожевников, В.В. Воробьев, А.Г. Чижиков, \\ Ю.М. Щекочихин, Е.М. Иванникова
}

\author{
ФГБНУ «Всероссийский научно-исследовательский институт электрификации сельского хозяйства» \\ 109456, Москва, 1-й Вешняковский проезд, 2, ВИЭСХ \\ Тел.: 8 (499) 171-19-20, e-mail: viesh@dol.ru, www.viesh.ru \\ ${ }^{1}$ Московский государственный машиностроительный университет (МАМИ) \\ 107023, Москва, Большая Семеновская ул., 38 \\ Тел.: 8 (499) 267-19-70, e-mail: iegh510@yandex.ru
}

doi: 10.15518/isjaee.2015.02.003

Заключение совета рецензентов: 29.04.15 Заключение совета экспертов: 05.05.15 Принято к публикации: 07.05 .15

Рассмотрены вопросы промышленного производства биомассы микроводорослей для использования в качестве энергетического сырья. Обсуждены экологические аспекты применения возобновляемой растительной биомассы в энергетике, показана необходимость замещения технологий сжигания топлива ископаемого происхождения технологиями возобновляемой энергетики. Проанализированы проблемы современной сырьевой базы биотопливной отрасли, ориентированной на продукцию сельского хозяйства продовольственного назначения. Показана возможность решения этих проблем за счет использования в энергетике биотоплив третьего поколения, производимых из биомассы водорослей. Обозначены основные направления исследований в целях снижения стоимости производства биотоплив третьего поколения и достижения конкурентоспособности на мировом энергетическом рынке.

Ключевые слова: микроводоросли, адаптивные свойства, культивирование, возобновляемая биомасса, биотопливо третьего поколения, экологическая эффективность, снижение себестоимости, технология производства, ресурсосбережение, полные циклы преобразования.

\section{PRODUCTION TECHNOLOGY AND USE OF FUEL-DEDICATED MICROALGAE BIOMASS}

\section{V.G. Chirkov, Yu.A. Kozhevnikov, V.V. Vorobyov, A.G. Chizhikov, Yu.M. Shchekochikhin, E.M. Ivannikova ${ }^{1}$}

\author{
The All-Russian research institute of electrification of agriculture (VIESH) \\ 109456, VIESH, $1^{\text {st }}$ Veshnyakovsky pr., 2, Moscow, Russia \\ Tel. 8 (499) 171-19-20; e-mail: viesh@dol.ru, www.viesh.ru \\ ${ }^{1}$ University of Mechanical Engineering \\ 107023, B. Semenovskaya St., Moscow, Russia \\ Tel. 8 (499) 267-19-70, e-mail: iegh510@yandex.ru
}

doi: 10.15518/isjaee.2015.02.003

Referred 29.04.15 Expertise 05.05.15 Accepted 07.05.15

Issues of industrial microalgae fuel-dedicated biomass production have been discussed in this paper. The environmental aspects of renewable plant biomass use have been analyzed and the importance of substitution of fossil fuels-based energy conversion cycles by renewable energy technologies has been substantiated. Problems of conventional biofuel production technologies oriented on use of food-dedicated agricultural products have been highlighted. These problems can be solved by using biofuels manufactured from microalgae. Main research directions aimed at raising competence of the third-generation of biofuels prepared from algae biomass have been described.

Keywords: algae, adoptability, cultivation, renewable biomass, third-generation biofuel, environmental efficiency, production cost reduction, manufacturing technology, energy saving, integrated closed conversion cycle. 


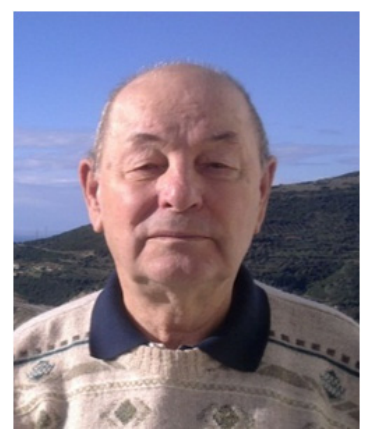

\section{Щекочихин Юрий} Михайлович

Yuri M. Shchekochikhin
Сведения об авторе: доктор, профессор ФГБНУ «Всероссийский научно-исследовательский институт электрификации сельского хозяйства».

Образование: Московский энергетический институт (1971).

Область научных интересов: технологические, экологические и нормативно-правовые аспекты возобновляемой энергетики, солнечная энергетика, новые источники возобновляемого органического сырья и технологии производства биотоплива, комбинированные циклы преобразования энергии.

Публикации: более 110 научных трудов и порядка 50 патентов.

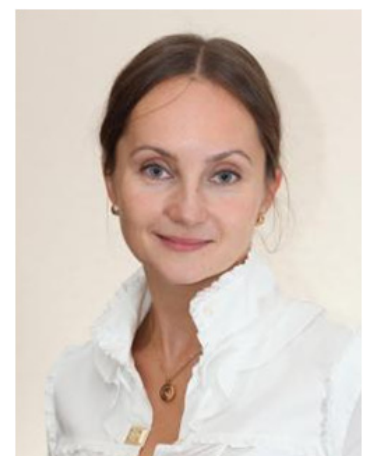

Сведения об авторе: к.т.н., доцент Московского государственного университета машиностроения (МАМИ)

Образование: Воронежский государственный университет (1999); Московский государственный университет инженерной экологии (ныне МАМИ)

Область научных интересов: инженерная экология, возобновляемые источники энергии, утилизация отходов

Публикации: 110.
Information about the author: Dr., Prof. in the All-Russian research institute of electrification of agriculture (VIESH).

Education: Moscow Power Engineering Institute (1971).

Research interests: technological, environmental and regulation aspects of renewable energy, solar energy, new sources of renewable biomass and biofuel production technologies, integrated energy conversion cycles.

Publications: more than 100 scientific papers and nearly 50 patents.

Information about the author: Ph.D., Assistant Professor in Moscow State University of Mechanical Engineering (MAMI).

Education: Voronezh State University (1999); Moscow State University of Environmental Engineering (MAMI).

Research interests: environmental engineering, renewable energy, waste management.

Publications: 110.

\section{Иванникова}

Елена Михайловна

Elena M. Ivannikova

Во второй половине XX столетия динамичный рост мировой экономики был обеспечен широким использованием легкодоступной и дешевой энергии ископаемого энергетического сырья - угля, нефти и газа. Нефть стала «кровью» транспортной инфраструктуры, без которой невозможно себе представить современную мировую экономику. Состояние рынка энергоносителей в существенной мере определяет ее развитие. Резкие колебания цены на нефть, учитывая уникальность этого вида энергетического сырья, порождают глубокие и продолжительные кризисы, затрагивающие практически все страны.

Большую обеспокоенность вызывают прогнозы экспертов относительно доступности источников энергии в будущем. Согласно этим прогнозам, при современных темпах потребления нефти хватит не более чем на 40, природного газа - на 60 и угля - на 170 лет [1]. В условиях интенсивного истощения земных недр перед человечеством стоят задачи перехода на энергосберегающие технологии и поиска новых энергетических источников. Конкретные меры по разработке и применению таких технологий с целью повышения эффективности использования энергии конечными потребителями стали применяться в развитых странах начиная с 70-х годов прошлого века, после очередного экономического кризиса. Одновременно происходит расширенное вовлечение в сферу энергетики возобновляемых источников (ВИЭ), использующих энергию солнца, ветра, водных потоков, морских течений, термальных и низкопотенциальных источников. В их числе биомасса занимает особое положение, поскольку, вопервых, используется человеком в качестве энергетического сырья с древнейших времен и, вовторых, это единственный вид ВИЭ, пригодный для производства моторных топлив.

Современная энергетика потребляет около 1 млрд. тонн растительной массы, что в топливном эквиваленте равноценно 25\% мировой добычи нефти. В частности, в странах экваториального пояса растительная биомасса остается основным источником энергии. Ее доля в энергобалансе развивающихся стран составляет $35 \%$, в мировом потреблении энергоресурсов - 12\%, а в России лишь $3 \%$ [2, 3]. При этом мировой потенциал 
растительной биомассы энергетического использования оценивается в 100 млрд. т.

Растительные организмы представляют собой первичную форму жизни на Земле и первый источник энергии, освоенный человеком. В соответствии с биогенной теорией формирования залежей топливного сырья, уголь, нефть и газ являются результатом преобразования осадочных пластов, содержащих останки живых (преимущественно растительных) организмов в условиях термического воздействия при повышенном давлении [4]. Не вдаваясь в детальный анализ физико-химических процессов, происходивших в течение десятков и сотен миллионов лет, можно рассматривать их как необходимое условие для возникновения живых организмов, которые не могут существовать без кислорода. Огромное количество углерода в форме углекислоты, составлявшей значительную часть атмосферной массы Земли, было изъято из нее в результате фотосинтеза и «запечатано» в земной коре в виде останков закончивших свой жизненный цикл растений. В соответствии с упрощенным уравнением фотосинтеза:

$6 \mathrm{nCO}_{2}+5 \mathrm{nH}_{2} \mathrm{O} \rightarrow\left[\mathrm{C}_{6} \mathrm{H}_{10} \mathrm{O}_{5}\right]_{\mathrm{n}}+6 \mathrm{nO}_{2}$, (1)

при образовании 1 кг биомассы (в сухом эквиваленте) поглощается около 1,83 кг $\mathrm{CO}_{2}$ и выделяется 1,1 кг $\mathrm{O}_{2}$. В уравнении (1) $\mathrm{C}_{6} \mathrm{H}_{10} \mathrm{O}_{5}$ представляет собой химическую формулу остатка глюкозы - элементарного звена полимерной цепочки макромолекулы целлюлозы, которая входит в число основных образующих компонентов растительной ткани. Из-за наличия в ее составе большого количества (до 50\%) кислорода, растительная биомасса, даже в «абсолютно сухом» виде, значительно уступает таким ископаемым видам топлива, как газ, нефть и уголь по теплотворной способности (таблица 1).

Теплотворная способность ископаемых и возобновляемых видов энергетического сырья

Таблица 1. Table 1.

Calorific value of fossil and renewable energy feedstock

\begin{tabular}{|l|c|c|c|c|}
\hline \multirow{2}{*}{ Вид сырья } & \multicolumn{3}{|c|}{ Состав, \% масс. } & Теплота сгорания (высшая), \\
\cline { 2 - 4 } МДж/кг
\end{tabular}

В результате длительного пребывания в земной коре органические компоненты теряли кислород, что приводило к постепенному повышению калорийности ископаемого топлива. Об этом можно косвенно судить, сравнив содержание кислорода в исходной растительной биомассе, в частности, древесине $(41 \%)$ и в торфе высокой степени разложения (25\%).

Биогенная теория происхождения ископаемых энергетических ресурсов прогнозирует неутешительный конечный итог их использования: полностью выработав залежи газа, нефти, углей и торфа, мы израсходуем при их сжигании весь атмосферный кислород и заменим его углекислым газом. Планомерное замещение ископаемого сырья возобновляемой растительной биомассой при ее постоянном воспроизводстве в объемах, превосходящих потребление, дает возможность сохранить неизменным состав атмосферы $[5,6]$ и избежать такого сценария. Кроме того, сам процесс получения энергии из растительной биомассы более безопасен экологически. Так, например, при ее сжигании выделяется менее $0,2 \%$ окислов серы и не более $3-5 \%$ золы, в то время как для угля значения этих показателей лежат в пределах 2-3 и 10-15\%, соответственно. Именно положительный экологический эффект от применения топлив из биомассы позволил достичь больших успехов в развитии биотопливной отрасли энергетики во многих странах, особенно в ЕС, где порядка $3 \%$ моторных топлив (биодизельное и биоэтанол) производится из возобновляемого растительного сырья, и США (биоэтанол).

В то же время, в результате существенного увеличения масштабов энергетического применения биомассы достаточно остро обозначились проблемы, связанные с вырубкой лесов и переводом значительной части сельхозпродукции из сферы пищевого и фуражного назначения в топливноэнергетическую. Происходящие изменения в структуре сельхозпроизводства имеют негативные социально-экономические последствия и приводят к разрушению экосистем, сложившихся на протяжении отрезков времени геологического масштаба и включающих в себя многие виды растений и животных. Поэтому весьма актуальны поиски новых хозяйственных циклов энергетического применения биомассы, не 
нарушающих

существенным

образом

технологических цепочек традиционного земледелия, ориентированного на производство продовольственных продуктов. Ввиду важности этой задачи, биотоплива, выработанные из непищевого сырья, выделены в отдельную группу, получившую название «биотоплив второго поколения».

Промышленностью освоены различные технологии производства биотоплива. В частности, биодизельное топливо получают путем переработки рапсового, соевого и других масел с получением метиловых эфиров жирных кислот (МЭЖК), которые добавляют в стандартное дизельное топливо в количестве от 5 до $20 \%$ (при более высоком содержании МЭЖК требуется соответствующая доработка топливной системы двигателя). Однако масштабное расширение производства масличных культур изменяет структуру растениеводства, вытесняя другие культуры из севооборота.

В этой связи актуальны поиски и промышленное освоение альтернативного растительного сырья высокой продуктивности для получения биотоплива. При этом особый интерес в этом плане представляют микроводоросли [7, 8]. Речь идет о биотопливах третьего поколения, вырабатываемых из растительных организмов, многократно превосходящих наземные культуры по своей продуктивности и вообще не требующих для культивирования посевных площадей. В 19781996 г.г. Министерство Энергетики США инвестировало более 25 млн. долларов в программу Aquatic Species Program (ASP) с целью разработки технологии приготовления биодизельного топлива из масла водорослей.

Микроводоросли (латинское название - algae) это группа автотрофных (обычно водных) организмов, содержащих специфические пигменты для поглощения солнечной энергии, которая используется для активации процессов фотосинтеза различных органических веществ (таблица 2). Являясь богатым источником белков и микроэлементов, водоросли широко используются в качестве пищевых компонентов. На основе водорослей производятся биологически активные добавки, красители и медицинские препараты. Некоторые штаммы водорослей имеют высокое содержание жиров и могут рассматриваться в качестве перспективного сырья для производства биодизельного топлива [9]. Именно возможность создания промышленного варианта такой технологии изучалась в большинстве проведенных до недавнего времени исследований (включая упомянутую программу ASP), которые показали нерентабельность такого производства в современных условиях из-за неприемлемо высокой себестоимости производства биодизельного топлива из микроводорослей, по меньшей мере, в 2-3 раза превышающей рыночные цены на стандартное дизельное горючее.

Учитывая опыт последних десятилетий, можно обозначить основные направления исследований в области снижения стоимости производства биотоплив третьего поколения и достижения их конкурентоспособности на мировом топливноэнергетическом рынке:

а) поиск существующих и селекция новых штаммов, оптимально отвечающих требованиям производства конкретного вида биотоплива;

б) снижение себестоимости культивирования биомассы микроводорослей биотопливного назначения, для чего необходимо:

- максимально использовать адаптивные свойства фотосинтезирующих микроорганизмов;

- разработать физико-химические методы воздействия на микроводоросли с целью повышения их продуктивности при снижении энергоемкости процесса культивирования;

- разработать технологии культивирования микроводорослей, обеспечивающие снижение эксплуатационных затрат по их культивированию, в том числе за счет использования свободных энергетических и инфраструктурных резервов конкретных хозяйственных объектов;

- разработать новые виды биотоплив третьего поколения с низкой себестоимостью и высокой экологической эффективностью, а также ресурсосберегающие технологии их производства;

в) разработка полных технологических циклов культивирования биомассы микроводорослей и еe преобразования в различные виды энергии, обеспечивающие максимальную утилизацию энергетических потерь, возникающих на всех стадиях преобразования энергии солнца (или искусственного источника света при закрытом способе культивирования) в энергию для конечного потребителя. 
Виды и химический состав микроводорослей

Algae strains and their chemical composition

\begin{tabular}{|c|c|c|c|c|}
\hline \multirow[b]{2}{*}{ Штамм } & \multicolumn{4}{|c|}{ Содержание компонентов, \% } \\
\hline & белки & углеводы & жиры & $\begin{array}{c}\text { нуклеиновые } \\
\text { кислоты }\end{array}$ \\
\hline Scenedesmus obliquus & $50-56$ & $10-17$ & $12-14$ & $3-6$ \\
\hline Scenedesmus quadricauda & 47 & - & 1.9 & - \\
\hline Scenedesmus dimorphus & $8-18$ & $21-52$ & $16-40$ & - \\
\hline Chlamydomonas rheinhardii & 48 & 17 & 21 & - \\
\hline Chlorella vulgaris & $51-58$ & $12-17$ & $14-22$ & $4-5$ \\
\hline Chlorella pyrenoidosa & 57 & 26 & 2 & - \\
\hline Spirogyra sp. & $6-20$ & $33-64$ & $11-21$ & - \\
\hline Dunaliella bioculata & 49 & 4 & 8 & - \\
\hline Dunaliella salina & 57 & 32 & 6 & - \\
\hline Euglena gracilis & $39-61$ & $14-18$ & $14-20$ & - \\
\hline Prymnesium parvum & $28-45$ & $25-33$ & $22-38$ & $1-2$ \\
\hline Tetraselmis maculata & 52 & 15 & 3 & - \\
\hline Porphyridium cruentum & $28-39$ & $40-57$ & $9-14$ & - \\
\hline Spirulina platensis & $46-63$ & $8-14$ & 4--9 & $2-5$ \\
\hline Spirulina maxima & $60-71$ & $13-16$ & $6-7$ & $3-4.5$ \\
\hline Synechoccus sp. & 63 & 15 & 11 & 5 \\
\hline Anabaena cylindrica & $43-56$ & $25-30$ & $4-7$ & - \\
\hline \multicolumn{5}{|c|}{ Штаммы с высоким содержанием жиров ( $\geq 50$ \%) } \\
\hline Ankistrodesmus braunii & & & 73 & \\
\hline Chlorella protothecoides & & & 58 & \\
\hline Neochloris oleoabundans & & & 54 & \\
\hline Pleurochrysis carterae & & & 50 & \\
\hline
\end{tabular}

Перспективность различных видов водорослей в качестве сырья для производства биодизельного топлива определяется следующими основными факторами:

- общая продуктивность в сухой массе на единицу площади;

- химический состав (в частности, содержание липидов);

- устойчивость к абиотическим параметрам среды культивирования, таким как климатические условия (температурный режим, давление, спектральный состав и интенсивность освещения, а также их пространственное распределение), химический состав воды (кислотность, солевой состав, концентрация растворенных газов), состав и плотность взвешенных твердых частиц;

- способность адаптироваться к биотическим факторам среды (а при выращивании в открытых водоемах - не нарушать равновесия сложившейся экосистемы);

- технологичность основных стадий полного цикла производства целевого продукта (конкретного вида биотоплива);

- энергетическая и экономическая эффективность полного цикла.
При отсутствии достаточного объема экспериментальных данных по перечисленным выше параметрам предварительная оценка перспективности конкретного штамма в качестве целевого биотопливного сырья может быть проведена в результате анализа опубликованных данных по абиотическим, биотическим, технологическим, экологическим и прочим показателям, используя многоуровневую бальную систему [10]. Так, при производстве биоэтанола показателем первого уровня может служить продуктивность штамма в условиях открытого (или тепличного) культивирования, показателем второго уровня - общее содержание углеводов. При производстве биодизельного топлива критерием первого уровня служит содержание жирных кислот. Вклад каждого из факторов того или иного условного уровня приоритетности определяют алгебраическим (с положительным или отрицательным знаком) суммированием баллов по всем уровням, используя разработанную для конкретной задачи систему коэффициентов. Возможное распределение критериев отбора штаммов по уровням приоритетности для некоторых задач представлено в таблице 3 . 
Таблица 3.

Критерии отбора штаммов микроводорослей для технологий производства органического сырья биотопливного назначения

Table 3.

Selection criteria for algae strains used as feedstock in biofuel production

\begin{tabular}{|c|c|c|c|}
\hline \multirow{2}{*}{ Показатели применения } & \multicolumn{3}{|c|}{ Приоритет критерия } \\
\hline & 1 & 2 & 3 \\
\hline \multicolumn{4}{|l|}{ Производство биодизельного топлива (культивирование в открытых системах) } \\
\hline Агрессивность по отношению к сложившейся природной биосистеме & -10 & & \\
\hline Высокая продуктивность в широком диапазоне температур & & +7 & \\
\hline Производство липидов на ед. площади & & & +5 \\
\hline \multicolumn{4}{|c|}{ Производство биодизельного топлива (культивирование в водоемах-теплицах) } \\
\hline Производство липидов на ед. площади & +10 & & \\
\hline Высокая продуктивность в широком диапазоне температур & & +5 & \\
\hline Продуктивность по сухой массе & & & +2 \\
\hline \multicolumn{4}{|c|}{ Производство биодизельного топлива на отходах сточных вод } \\
\hline Способность ассимилировать соединения азота и др. компоненты сточных вод & +10 & & \\
\hline Производство липидов на ед. площади & & +8 & \\
\hline Высокая продуктивность в широком диапазоне температур & & & +5 \\
\hline \multicolumn{4}{|l|}{ Производство биогаза на отходах сточных вод } \\
\hline Способность ассимилировать соединения азота и др. компоненты сточных вод & +10 & & \\
\hline Продуктивность по сухой массе & & +8 & \\
\hline Высокая продуктивность в широком диапазоне температур & & & +5 \\
\hline
\end{tabular}

Задача селекционной работы состоит в создании культур микроводорослей, обладающих оптимальными (заданными) для конкретного применения свойствами. В частности, для производства биодизельного топлива требуются штаммы с повышенным содержанием липидов без потери продуктивности в условиях модулированного питания. В работе [11] произведено исследование различных штаммов микроводорослей, наиболее полно отвечающих требованиям производства биодизельного топлива по содержанию жиров (нижняя часть таблицы 2). Лидирующая роль принадлежит диатомовым и зелёным водорослям.

Интересны результаты исследований способности ацетил-СоА карбоксилазы и биотинсодержащего фермента оказывать каталитическое действие на начальные стадии биосинтеза липидов. Теоретически возможно, используя методы генной инженерии, интенсифицировать процесс синтеза жиров микроводорослями за счет селективного усиления активности этих ферментов. На водоросли эукариоте Cyclotella cryptica были проведены исследования клонирования гена, кодирующего ацетил-СоА карбоксилазу, после его экстракции. Было найдено, что аминокислотная последовательность ацетил-СоА карбоксилазы этого гена в высокой степени схожа с аминокислотной последовательностью ацетил-СоА карбоксилазы животных и дрожжей в доменах биотин карбоксилазы и карбоксилтрансферазы. Сравнение геномных нуклеотидных последовательностей клонов к ДНК выявило присутствие в гене двух интронов. В настоящее время исследователи конструируют векторы усиления этих генов, при этом целью является разработка геномных протоколов преобразования в водорослях, которые позволят усилить активность ацетил-СоА карбоксилазы Cyclotella cryptica и других видов водорослей.

Возможность использования адаптивных свойств микроводорослей с целью управления химическим составом и продуктивностью биотехнологическими методами продемонстрирована в лабораторных условиях [12]. Показано, в частности, что при снижении доступности азотсодержащих субстратных биогенных веществ некоторые штаммы водорослей могут синтезировать до $65 \%$ жиров.

Мало исследованы, обладающие большим потенциалом воздействия на энергетические характеристики процесса фотосинтеза, такие методы, как модуляция электростатическим полем, электромагнитными полями в различных диапазонах, включая область видимого оптического спектра, в котором происходит генерация носителей заряда, запускающих окислительновосстановительные процессы [13].

Решить задачу обеспечения конкурентоспособности биотоплив третьего поколения можно, если использовать биомассу микроводорослей в качестве возобновляемого энергетического сырья для приготовления котельных композитных минерально-органических биотоплив, обладающих значительно более высокими экологическими параметрами по сравнению со стандартными топливами ископаемого происхождения [14]. При сжигании таких биотоплив выбросы вредных веществ (моноокиси углерода, окислов серы и азота, сажи и др.) в атмосферу могут быть существенно снижены. Затраты на производство такой энергетической продукции можно минимизировать, максимально используя в технологиях низкотемпературные процессы, такие как гидродинамическое и ультразвуковое 
воздействие на многокомпонентные многофазные среды.

В качестве примера наиболее эффективного применения данной концепции можно привести цикл теплоэлектрогенерации, включающий стадию производства и переработки биомассы микроводорослей [15]. Такой цикл может быть организован на базе мазутной ТЭС. Установки по культивированию микроводорослей могут быть обустроены на площадях землеотведения с использованием водоемов охладителей, площадь которых по нормативам составляет от 6 до 9 м²/кВт. Электрический кпд ТЭС составляет $35 \ldots 40 \%$. При этом около двух третей энергии химических связей органического топлива преобразуется в тепло. Из них около $10 \%$ уходит с дымовыми газами. Для конденсации отработавшего пара используют воду из естественного водоема, которая уносит и рассеивает в окружающей среде значительное количество тепла. Данный энергетический ресурс, не представляющий интереса с точки зрения использования в промышленных целях, мог бы найти применение для поддержания жизнедеятельности микроводорослей в течение продолжительного среднегодового периода. Согласно оценкам, для производства тепличным способом $1 \mathrm{~T}$ сухой массы микроводорослей в умеренном климате требуется около 400 Гкал тепловой энергии. Около $80 \%$ этой потребности может быть покрыто за счет сбросного тепла ТЭС. При этом эксплуатационные затраты производства снижаются, по крайней мере, на 30\%.

\section{Список литературы}

1. Ола Дж., Гепперт А., Пракаш С. Метанол и энергетика будущего. Когда закончатся нефть и газ. Пер. с англ. М.: БИНОМ. Лаборатория знаний. 2009.

2. Watson R.T., Zinyowera M.C., and Moss R.H. (Eds.). Climate change 1995: Impacts, adaptations and mitigation of climate change: Scientific-technical analyses. Contribution of working group II to the second assessment report of the intergovernmental panel on climate change. IPCC. Cambridge, UK. Cambridge University Press. 1995.

3. Энергетическая стратегия России на период до 2020 г. Распоряжение правительства РФ № 1234-p, 28.08.2003.

4. Libes S. Introduction to Marine Biogeochemistry. 2009. Academic Press. (ISBN 9780120885305)

5. Paustian K., Cole C.V., Sauerbeck D., SampsonN. $\mathrm{CO} 2$ mitigation by agriculture: an overview // Climatic Change 40. 1998. P. 135-162.

6. Иванникова Е.М., Систер В.Г., Чирков В.Г. Альтернативные топлива для двигателей внутреннего сгорания // Альтернативная энергетика и экология. 2013. № 13. C. 33-42. DOI: 10.15518/ISJAEE (R). 1.20140601006 .

7. Моисеев И.И., Платэ Н.А. Топливо будущего // Химический журнал. 2006. № 6. С. 45-53.

8. Berndes G., Hoogwijk M., Broek R. The
При этом ТЭС может работать на композитном минерально-органическом биотопливе на основе гомогенной смеси стандартного котельного топлива (мазута) и эмульсии микроводорослей, обеспечивая дополнительное сокращение эксплуатационных затрат по выработке тепловой и электрической энергии.

Общая схема технологии по производству тепла и электроэнергии включает установку по культивированию микроводорослей с использованием открытого водоема или водоематеплицы. Из произведенной биомассы микроводорослей путем отделения значительной части влаги готовят концентрат требуемой плотности, определяемой соотношением углеводородной и водосодержащей фракций в композитном биотопливе. Это обеспечивает экономию мазута до $20 \%$ при работе котельной установки при снижении вредных выбросов в атмосферу за счет более полного сгорания. В частности, содержание сажи при использовании водосодержащего биотоплива снижается в 2-3 раза. Котельная установка производит пар для электрогенерирующего агрегата. Сбросное тепло контура охлаждения агрегатов энергогенерирующей системы в виде горячей воды используется для поддержания требуемого оптимального температурного режима в установке по культивированию микроводорослей. Из образующейся при сжигании золы извлекают минеральные биогенные компоненты, необходимые для синтеза биомассы микроводорослей.

\section{References}

1. Ola Dž., Geppert A., Prakaš S. Metanol i ènergetika buduŝego. Kogda zakončatsâ neft' i gaz. Per. s angl. M.: BINOM. Laboratoriâ znanij. 2009.

2. Watson R.T., Zinyowera M.C., and Moss R.H. (Eds.). Climate change 1995: Impacts, adaptations and mitigation of climate change: Scientific-technical analyses. Contribution of working group II to the second assessment report of the intergovernmental panel on climate change. IPCC. Cambridge, UK. Cambridge University Press. 1995.

3. Ėnergetičeskaâ strategiâ Rossii na period do 2020 g. Rasporâženie pravitel'stva RF № 1234-r, 28.08.2003.

4. Libes S. Introduction to Marine Biogeochemistry. 2009. Academic Press. (ISBN 9780120885305)

5. Paustian K., Cole C.V., Sauerbeck D., SampsonN. $\mathrm{CO} 2$ mitigation by agriculture: an overview // Climatic Change 40. 1998. R. 135-162.

6. Ivannikova E.M., Sister V.G., Čirkov V.G. Al'ternativnye topliva dlâ dvigatelej vnutrennego sgoraniâ // Al'ternativnaâ ènergetika i èkologiâ. 2013. № 13. S. 33-42. DOI: 10.15518/ISJAEE (R). 1.20140601006 .

7. Moiseev I.I., Platè N.A. Toplivo buduŝego // Himičeskij žurnal. 2006. № 6. S. 45-53. 
contribution of biomass in the future global energy supply: a review of 17 studies // Biomass and Bioenergy 25. 2003. P. 1-28.

9. Ratledge C., Cohen Z. Microbial and algal oils: do they have a future for biodiesel or as commodity oils? // Lipid Technology. 2008. Volume 20, Issue 7. P. 155-160.

10. Чирков В.Г., Росс М.Ю., Плотников С.П. Оценка перспективности различных видов микроводорослей для производства биотоплива / Энергообеспечение и энергосбережение в сельском хозяйстве // Труды 7-й Международной научнотехнической конференции (18-19 мая 2010 г. Москва, ГНУ ВИЭСХ. ч. 4 (Возобновляемые источники энергии, местные энергоресурсы, экология). С. 312318.

11. Beer T., et. al. Biodiesel from algae. CSIRO Aspendale Laboratories, Regional Forum on Bioenergy Sector Development: Challenges, Opportunities, and Way Forward. 2008. P. 1-14.

12. Leon-Banares R., et. al. Transgenic microalgae as green cell-factories. // Trends in Biotechnology. 2004. 22(1). P. 45-52.

13. Li Z., Guo S., Lin L., et al. Effects of electromagnetic field on the batch cultivation and nutritional composition of Spirulina platensis in an airlift photobioreactor // Bioresour. Technol. 2007. Vol. 98. P. 700-705.

14. Систер В.Г., Иванникова Е.М., Чирков В.Г., Кожевников Ю.А. Приготовление композитных котельных и моторных биотоплив из альгамассы // Альтернативная энергетика и экология. 2013. № 1 (2 часть). С. 103-107.

15. Систер В.Г., Иванникова Е.М., Чирков В.Г., Кожевников Ю.А. Использование микроводорослей в энергогенерирующих циклах, потребляющих жидкое углеводородное топливо ископаемого происхождения // Альтернативная энергетика и экология. 2013(131). № 9. С. 36-41.
8. Berndes G., Hoogwijk M., Broek R. The contribution of biomass in the future global energy supply: a review of 17 studies // Biomass and Bioenergy 25. 2003. R. 1-28.

9. Ratledge C., Cohen Z. Microbial and algal oils: do they have a future for biodiesel or as commodity oils? // Lipid Technology. 2008. Volume 20, Issue 7. R. 155160.

10.Čirkov V.G., Ross M.Û., Plotnikov S.P. Ocenka perspektivnosti različnyh vidov mikrovodoroslej dlâ proizvodstva biotopliva / Ènergoobespečenie i ènergosbereženie $v$ sel'skom hozâjstve // Trudy 7-j Meždunarodnoj naučno-tehničeskoj konferencii (18-19 maâ 2010 g. Moskva, GNU VIÈSH. č. 4 (Vozobnovlâemye istočniki ènergii, mestnye ènergoresursy, èkologiâ). C. 312-318.

11. Beer T., et. al. Biodiesel from algae. CSIRO Aspendale Laboratories, Regional Forum on Bioenergy Sector Development: Challenges, Opportunities, and Way Forward. 2008. R. 1-14.

12.Leon-Banares R., et. al. Transgenic microalgae as green cell-factories. // Trends in Biotechnology. 2004. 22(1). R. 45-52.

13.Li Z., Guo S., Lin L., et al. Effects of electromagnetic field on the batch cultivation and nutritional composition of Spirulina platensis in an airlift photobioreactor // Bioresour. Technol. 2007. Vol. 98. P. 700-705.

14.Sister V.G., Ivannikova E.M., Čirkov V.G., Koževnikov Û.A. Prigotovlenie kompozitnyh kotel'nyh i motornyh biotopliv iz al'gamassy // Al'ternativnaâ ènergetika i èkologiâ. 2013. № 1 (2 čast'). S. 103-107.

15.Sister V.G., Ivannikova E.M., Čirkov V.G., Koževnikov Û.A. Ispol'zovanie mikrovodoroslej $\mathrm{V}$ ènergogeneriruûŝih ciklah, potreblâûsih židkoe uglevodorodnoe toplivo iskopaemogo proishoždeniâ // Al'ternativnaâ ènergetika i èkologiâ. 2013(131). № 9. S. $36-41$. 